\title{
TRADIÇÃO NO KUNG FU: MESTRES BRASILEIROS ENTRE PERMANÊNCIAS E TRANSFORMAÇÕES
}

\author{
TRADITION IN KUNG FU: BRAZILIAN MASTERS BETWEEN CONTINUITIES \\ AND CHANGES
}

TRADICIÓN EN EL KUNG FU: MAESTROS BRASILEÑOS ENTRE
PERMANENCIAS Y TRANSFORMACIONES

Marcio Antonio Tralci Filho*

Palavras-chave

Artes marciais.

Narrativas pessoais.

História do século

XIX: China.
Resumo: Esse artigo se propõe a investigar e analisar a concepção de mestres brasileiros sobre a tradição nas artes marciais chinesas. Para tanto, foram entrevistados cinco mestres brasileiros, discípulos de chineses, dos quais foram registradas, por meio de história oral temática, suas visões acerca do objeto em questão. 0 cotejamento dessas narrativas com o referencial teórico adotado possibilitou analisar que as concepções dos mestres sobre a tradição gravitam em torno da manutenção do passado e das perspectivas de mudança da arte marcial ao longo do tempo, trazendo à tona uma sofisticada articulação entre estrutura e transformação.

Abstract: This article investigates and analyzes Brazilian masters' views on tradition in Chinese martial arts. The five Brazilian masters interviewed were disciples of Chinese masters, and their views about the subject were recorded through thematic oral history. A comparison of those narratives to the theoretical framework showed that masters' views about tradition surround maintenance of the past and changing the perspectives of martial arts over time, thus creating an elaborate relationship between structure and change.

Resumen: Ese artículo se propone investigar y analizar la concepción de maestros brasileños a respecto de la tradición en las artes marciales chinas. Con este fin, fueron entrevistados cinco maestros brasileños, discípulos de maestros chinos, de quienes se registraron, a través de historia oral temática, sus visiones acerca del objeto en cuestión. Cotejar esas narrativas con el referencial teórico adoptado permitió analizar que las concepciones de los maestros a respecto de la tradición gravitan alrededor de la manutención del pasado y de las perspectivas de cambio del arte marcial a lo largo del tiempo, trayendo a la superficie una sofisticada articulación entre estructura y transformación.
* Universidade de São Paulo. São Paulo, SP, Brasil.

E-mail: matfilho@usp.br

Recebido em: 06-04-2015 Aprovado em: 18-09-2015 (c) (1) (8) Licence 


\section{INTRODUÇÃ $0^{1}$}

O Kung Fu, nome pelo qual é reconhecido o conjunto dos variados sistemas, escolas e famílias de artes marciais de origem chinesa, adquiriu grande repercussão a partir das décadas de 1960 no Brasil devido, em grande medida, tanto à apropriação promovida pela indústria cultural por meio de revistas em quadrinhos, séries de televisão e filmes de cinema, como pelo fluxo migratório de chineses para o país, que contou com a chegada de mestres de artes marciais (APOLLONI, 2004, MARTA, 2009, FERREIRA, 2013).

Esses fenômenos estão relacionados com as transformações ocorridas na China desde meados do século XIX, período em que os intentos coloniais das nações europeias, aliados ao descrédito em relação ao Império Chinês, deram origem a uma série de conflitos de ordem interna e externa. Fairbank e Goldman (2008) apontam para uma "desmoralização" não apenas econômica, como também política e intelectual do Império como decorrência desses eventos, culminando com a assinatura de acordos e reformas que acentuavam a colonização. Pouco tempo depois, em 1911, houve a queda do regime imperial e do sistema feudal para a instalação de um governo republicano nacionalista e, em 1949, após outro período de guerras civis, foi fundada a República Popular de orientação maoísta.

A rápida transformação social, econômica, política e cultural teve reflexos importantes sobre as concepções a respeito das práticas corporais chinesas e as artes marciais tomaram o centro das discussões. Elevadas à categoria de "cultura física nacional" (MORRIS, 2004, p. 242), foram alvo de diversas tentativas de modificação em direção ao modelo esportivo competitivo europeu, com o intuito de "modernizá-las". Contudo, a diáspora chinesa ocorrida após esse período alterou o panorama das artes marciais em nível global, uma vez que a migração de mestres para Hong Kong, para a América e para a Europa estabeleceu um contraponto a esse modelo esportivo, levado a cabo pela padronização do Kung Fu instituída tanto pelo Estado republicano quanto pelo maoísta (MORRIS, 2004, BROWNELL, 2008). No caso do Brasil, diversos mestres oriundos dessa diáspora vieram a encontrar no país condições para difusão de suas práticas tal qual era realizada antes dessa reestruturação, ainda que tenham vivenciado e, possivelmente, incorporado as transformações das artes marciais na China. Tal difusão se deu, entre outros fatores, a partir do contato e da formação de discípulos brasileiros (FERREIRA, 2013).

Além de ter em vista esse recorte histórico, a presente pesquisa surgiu a partir de inquietações que o autor teve, enquanto "pesquisador-praticante" de artes marciais, no contato com seu mestre brasileiro, discípulo de um mestre chinês, o que permitiu a formulação de algumas questões norteadoras: quando o mestre diz que tal técnica é tradicional, a que ele se refere? O que ele entende por tradicional? Qual é a importância da tradição para o Kung Fu? Com foco nessas questões, este artigo objetiva investigar e analisar a concepção de mestres brasileiros, discípulos de chineses, sobre a tradição nas artes marciais chinesas.

\section{REFERENCIAIS TEÓRICO-METODOLÓGICOS}

De caráter qualitativo, a pesquisa foi conduzida a partir de entrevistas com mestres brasileiros de Kung Fu, discípulos de chineses, entre agosto de 2012 e setembro de 2013. A 
escolha dos sujeitos se deu baseada em critérios de diversidade de sistemas consagrados de Kung Fu, ou seja, deu-se preferência por mestres que representem nacionalmente estilos de artes marciais chinesas variados entre si. Desse modo, foi dada ênfase para a amplitude de visões sobre a arte marcial, tendo em vista a elaboração de um esboço abrangente do panorama de narrativas sobre a tradição no Kung Fu. Os mestres selecionados foram os seguintes:

Leo Imamura - É o líder do Clã Moy Yat Sang de Ving Tsun e o único discípulo do Grão Mestre Moy Yat no Brasil. Entrou em contato com as artes marciais a partir da admiração pelo ator Bruce Lee e do contato com diversas manifestações de luta no ensino médio do Colégio Objetivo de São Paulo, onde artes coreanas, japonesas e chinesas eram extensamente praticadas pelos estudantes. Nessa época iniciou, após breves, mas importantes, passagens pelo Judô e Caratê, seus estudos no Ving Tsun com Mestre Li Hon Ki, irmão do também Mestre Li Wing Kay. Em viagem a Hong Kong, a convite do irmão de seu mestre, Imamura fez uma escala em Nova lorque e acabou conhecendo aquele de quem se tornaria discípulo no ano de 1988: o Grão Mestre Moy Yat. Após estabelecer uma relação muito próxima com ele e se dedicar integralmente ao Ving Tsun, Mestre Imamura recebeu a incumbência do Grão-Mestre Moy Yat de criar um programa que enfatizasse os aspectos do que denominavam de "Vida Kung Fu" e, no ano de 2003, desenvolveu e implantou o "Programa Moy Yat Ving Tsun de Inteligência Marcial". Desde então, o clã liderado por ele já formou diversos mestres no Brasil, os quais lideram seus próprios núcleos.

Angela Soci -É discípula do Grão-Mestre Yang Jun, da Família Yang de Tai Chi Chuan. É diretora da Sociedade Brasileira de Tai Chi Chuan e Cultura Oriental, do Yang Cheng Fu Tai Chi Chuan Center de São Paulo e diretora de Assuntos Latino-americanos da Internacional Yang Family Tai Chi Chuan Association. Iniciou sua prática em Tai Chi Chuan após interromper sua graduação em Psicologia, em uma busca por aquilo que fazia sentido em sua vida. A relação com o Grão-Mestre Yang Jun e seu avô, o Grão-Mestre Yang Zhenduo se iniciou em uma viagem para a China, possibilitada pelo seu esposo e, até então, mestre, Roque Severino. Após contato e práticas intensos com ambos os mestres na China, passou a trazê-los para seminários anuais no Brasil até que, em 2010, ela e Roque foram convidados a serem discípulos do Grão-Mestre Yang Jun. Em algumas ocasiões pode notar que o fato de ser mulher confere desconfiança sobre sua capacidade de prática do Tai Chi Chuan. Mais recentemente, no ano de 2013, Mestra Angela Soci foi a primeira pessoa a obter o título de "Senior Instructor" pela International Yang Family Tai Chi Chuan Association. Apesar de ter formado diversos alunos na Sociedade Brasileira de Tai Chi Chuan e Cultura Oriental - fundada por ela e Roque Severino e local onde leciona - e de seu notório saber e prática no Tai Chi Chuan, Angela Soci preferiu ser chamada de "professora" e não de "mestra".

Francisco Nobre - É representante internacional do estilo Garra de Águia da Família Lau e discípulo da Grã-Mestra Lily Lau. Iniciou sua prática em artes marciais por conta própria, a partir de filmes e livros ainda na sua cidade natal, Mineirolândia, no sertão cearense. 0 Kung Fu passou a significar tanto em sua vida que decidiu migrar para São Paulo, com auxílio financeiro da mãe e de uma vizinha, com o objetivo de aprender com um mestre. Conciliando os trabalhos como entregador de móveis, auxiliar de serviços gerais em uma marmoraria e ajudante de cozinheiro na Brahma, Francisco iniciou seus treinamentos com o Grão-Mestre Li Wing Kay em 1993, com o qual alcançou diversos títulos como atleta em campeonatos nacionais e internacionais, bem como começou a administrar academias de seu mestre, 
momento no qual decidiu abandonar outros trabalhos remunerados e viver somente do Kung Fu. Em 2003, Mestre Francisco cortou relações com o Grão-Mestre Li e, dois anos depois, passou a entrar em contato com a Grã-Mestra Lily Lau, em uma relação consolidada em 2010, quando Mestre Francisco Nobre se torna seu discípulo, em cerimônia ocorrida diante do túmulo do pai de Mestra Lau, o Grão-Mestre Lau Fat Mang, em Hong Kong. Atualmente, ministra aulas em sua própria academia no bairro de Santa Cecília, em São Paulo. Nessa entrevista, estava presente o Mestre Sérgio Queiroz, também do Garra de Águia da Família Lau, que contribuiu nas discussões sobre tradição.

Paulo da Silva - É discípulo do Grão-Mestre Chiu Chi Ling do estilo Hung Gar e seu representante exclusivo para a América do Sul. Seu contato inicial com as artes marciais se deu pelo Karate Shinkyu Shotokan, na cidade de Cabo de Santo Agostinho, em Pernambuco. Devido à situação econômica de sua família e à possibilidade de conquistar melhores condições de vida em São Paulo, viajou, a convite de um irmão, para morar na capital paulista em 1978. Começou a praticar Kung Fu por insistência do irmão, que havia encontrado uma academia próximo de onde residiam. Após algum tempo e graças à sua experiência prévia com o caratê, Paulo se destacou e foi convidado pelo Mestre Miguel de Lucas a assumir a escola, enquanto trabalhava como ajudante em mecânica e encanador. Mestre Paulo acabou se distanciando de seu primeiro mestre, que retornou ao Chile, mas se envolveu na fundação das primeiras federações e confederações do Brasil. Algum tempo depois, Mestre Paulo viajou para os EUA e conheceu o Grão-Mestre Chiu Chi Ling, ao qual se filiou. Sua história nas artes marciais, enquanto praticante ou mestre, é atravessada pela discriminação racial e xenofobia que sofreu pelo fato de ser negro e nordestino. Atualmente preside a Liga Nacional de Kung Fu e organiza campeonatos nacionais anuais com a presença de seu mestre.

Thomaz Chan -É discípulo de seu pai, o Grão-Mestre Chan Kwok Wai do estilo Shaolin do Norte, e Diretor Técnico Geral da Confederação Brasileira de Kung Fu/Wushu. Ainda na infância foi enviado à sua revelia para estudar cantonês em Hong Kong, onde teve contato com alguns mestres de Kung Fu amigos de seu pai e, de volta ao Brasil, iniciou a prática do Shaolin do Norte com Grão-Mestre Chan. Em outra viagem à China, entrou em contato com o Wushu Moderno/competitivo na Beijing University of Physical Education (atualmente Beijing Sport University), vertente que o consagraria como um dos grandes expoentes do Kung Fu em nível competitivo, tanto como atleta como no papel de treinador. Com isso, construiu certa independência da figura de seu pai e começou, após alguma hesitação, a se dedicar formalmente à formação e ao treinamento de novos atletas de Wushu Moderno a partir do ano de 1998, sem, contudo, abandonar os ensinamentos do Kung Fu transmitido por GrãoMestre Chan Kwok Wai. Na mesma época, fez parte do círculo de mestres que fundaram as primeiras federações e confederações de Kung Fu no Brasil. Atualmente, além de fazer parte dos quadros da Diretoria da CBKW, administra e leciona em sua própria academia no bairro da Pompeia, em São Paulo.

As entrevistas foram conduzidas em dois momentos consecutivos: inicialmente a partir da história oral de vida dos mestres brasileiros, baseado em Meihy e Holanda (2007), Bosi (2004) e Rubio (2006), seguido por história oral temática (MEIHY; HOLANDA, 2007) a respeito da tradição. A história oral pode ser compreendida como um processo de transição do oral para o escrito, captado por meio das fontes orais, entre elas a entrevista, com o fim de registrar e produzir documentos para fins analíticos (MEIHY; HOLANDA, 2007). Esse método de investigação é 
aqui utilizado tendo em vista a suas possibilidades em abordar as aproximações e afastamentos entre a memória individual e a memória coletiva (HALBWACHS, 2006). A história oral vem sendo recentemente utilizada na área de Educação Física como instrumento privilegiado para investigar temas referentes ao universo sociocultural do protagonismo de atletas e treinadores (NASCIMENTO, 2012, LIMA, 2012), às artes marciais (NUNES, 2011) e, especificamente, ao Kung Fu (FERREIRA, 2013). Ferreira, Marchi Junior e Capraro (2014) apontam, inclusive, para a pertinência em se utilizar a história oral como método de pesquisa em artes marciais, dado 0 predomínio da oralidade tanto em sua história como em suas práticas pedagógicas.

Por uma questão de enquadramento no formato de artigo, foram selecionadas apenas as narrativas referentes à história oral temática, sem deixar de ressaltar que as narrativas sobre as histórias de vida abriram o caminho para um diálogo mais fluido e espontâneo entre pesquisador e mestres. Para abordar especificamente a tradição, três questões foram elaboradas:

1. "O que é tradição para você?"

2. "Na sua opinião, a tradição é importante no Kung Fu? Por quê?"

3. "Qual é, na sua opinião, a diferença entre um Kung Fu tradicional e um Kung Fu não tradicional?"

Todas as entrevistas foram transcritas e passaram por um processo de reescrita que envolveu a reorganização da narrativa com o intuito de deixá-la esteticamente aprimorada e melhorar a compreensão do que foi dito, admitindo o registro, inclusive, da comunicação não verbal e da intenção da fala dos entrevistados, processo denominado por Meihy e Holanda (2007) como "transcriação". O texto produzido após essa tradução do oral para o escrito foi enviado para os entrevistados. Mestre Leo Imamura solicitou uma nova entrevista para melhorar o texto, Professora Angela Soci apontou correções no texto enviado e os Mestres Francisco Nobre e Paulo da Silva aprovaram a história tal qual constava no arquivo enviado pelo autor. Todo o material utilizado para análise é proveniente dessa avaliação e aprovação pelos entrevistados.

O panorama elaborado a partir dessas narrativas foi construído e analisado a partir da noção de "campo esportivo" de Bourdieu (2004). Tal conceito busca relacionar as dinâmicas de determinada prática corporal com seu contexto social, de modo que "a distância social se traduz na lógica dos esportes" (BOURDIEU, 2014, p. 209). Nessa concepção, estrutura e transformação não são conceitos opostos, de modo que não se compreende a estrutura sem compreender as suas transformações. Esse aporte teórico é relevante para esta pesquisa, uma vez que, ao tratar do tema da tradição - uma fração do campo das artes marciais chinesas -, as noções de permanência e transformação são centrais e a perspectiva de ampliar o panorama da análise das práticas corporais, tal como propõe Bourdieu (2014), é indispensável para situar essa dinâmica em uma análise sincrônica - no espaço e tempo da história de vida dos mestres - e diacrônica - em relação à história do Kung Fu. Nesse sentido, esse referencial possibilita uma análise pertinente sobre as relações entre a história recente das artes marciais chinesas e a história oral a partir das narrativas dos mestres brasileiros, ou seja, o trânsito entre suas memórias individuais e a memória coletiva do Kung Fu.

Desse modo, foi possível estabelecer um estudo mais detido sobre a tradição no Kung Fu, suas permanências e suas transformações. Para uma análise aprofundada do conceito, 
as narrativas dos mestres foram entretecidas com o referencial teórico da pesquisa, a saber, os textos de Gadotti (1975) sobre a relação entre mestre e discípulo e de Arendt (2011) sobre a autoridade, bem como as obras de Hobsbawm (2006) e Thompson (1998) a respeito das noções de tradição inventada e costumes.

Em relação aos cuidados éticos, além dos procedimentos de avaliação e devolutiva dos textos produzidos a partir das entrevistas, todos os entrevistados assinaram e mantiveram uma cópia do Termo de Consentimento Livre e Esclarecido de acordo com o estabelecido pelo Comitê de Ética em Pesquisa da Escola de Educação Física e Esporte da USP, o qual aprovou a realização da pesquisa.

\section{ANÁLISE E DISCUSSÃO}

Tradição: o passar do tempo e a autoridade dos antepassados

De início, os mestres concordam ao afirmar que a tradição é elemento constitutivo da legitimidade da prática. Os imperativos da relação com o tempo e da autoridade dos antepassados são elementos trazidos à tona em quase todas as narrativas e parecem ser centrais nas considerações dos mestres sobre a importância da tradição em suas práticas.

Sobre a relação com o tempo, uma fala de Mestre Paulo da Silva é ilustrativa de sua relevância. Considerando a si próprio como tradicional em razão dos seus mais de 40 anos de dedicação às artes marciais, demarca a importância do "passar do tempo" para adquirir experiência e é a própria experiência adquirida que é considerada tradição: a sua constituição está no empenho e no trabalho desenvolvido por aquele que se disponibiliza a iniciar uma prática.

Então, passando dificuldade ou não, você está sendo persistente naquilo que você está fazendo e aquilo se torna uma tradição, se torna um costume. Eu acho que você fica bem fanático naquilo, de acordo com o que você está fazendo, com 0 tempo. Porque o tempo é que nos dá a experiência, é que nos traz a experiência. $A$ experiência é com o tempo você vai adquirir. Se você vai adquirir isso com o tempo, é tradição (Mestre Paulo da Silva. Entrevista em 17/09/2013).

Mestre Sérgio Queiroz evidencia o eixo temporal da tradição quando coloca em perspectiva a aparente arbitrariedade na delimitação dos critérios que conferem a uma ramificação das artes marciais chinesas um caráter tradicional ou não. Ao observar com cautela que uma prática recente não pode ser vista como tradicional, pondera:

Então, vamos supor que tu digas que o Jeet Kune Do, que foi a arte criada pelo Bruce Lee, não é considerada uma arte tradicional chinesa. Não é considerada, quando? Hoje ou daqui a 200 anos? Essa é a pergunta, tá entendendo? Por quê? Porque tradição também tem a ver com tempo, longevidade, manutenção (Mestre Sérgio Queiroz. Entrevista em 11/07/2013).

Mestre Leo Imamura contribui com essa necessidade de se atentar para a antiguidade de uma prática quando alude para a observação da genealogia de um sistema de artes marciais. Remetendo-se ora a conceitos caros à Família Moy Yat Ving Tsun - como o de "Mobilização Interpessoal Indireta" - ação na qual um sujeito mobiliza outro no sentido de este mobilizar um terceiro - ora a "qualquer estudo genealógico", Mestre Imamura vislumbra que o tempo para se considerar tradicional uma arte marcial, ou qualquer outra relação que envolva legado, é o decorrente de cinco gerações. 
[Explica utilizando os dedos de uma mão] Então, a partir do momento que eu aprendo, eu tenho que aprender a transmitir para uma segunda pessoa, só que essa segunda pessoa aqui, ela também tem que saber como transmitir para essa terceira, então não adianta só essa primeira pessoa aprender a transmitir para a segunda; a primeira tem que garantir que essa segunda daqui transmita para essa terceira, que é o nós chamamos de Mobilização Interpessoal Indireta. [...] Então são três momentos, só que o que adianta, se eu fizer isso e esse daqui, o segundo, fizer isso e esse terceiro aqui, ele vai parar nele, quer dizer, ele não sabe fazer a Mobilização nem Interpessoal Direta e nem Indireta? Eu preciso que esse aqui, que esse primeiro que iniciou, ele garanta que esse aqui, o terceiro, saiba fazer a Mobilização Interpessoal Direta, com um quarto, e a Indireta com um quinto. Quando isso acontecer, cumpriu o ciclo. Quer dizer, esse sistema não morre mais, por isso que são cinco gerações (Mestre Leo Imamura. Entrevista em 17/08/2012).

A tradição nas artes marciais é, portanto, atravessada por uma demanda temporal que, pela sua inexorabilidade, coloca à prova a legitimidade de um sistema mais recente, por mais genuína e circunspecta que seja, e valida um sistema pela sua antiguidade, respaldada pelas gerações que o salvaguardaram. Entretanto, juntamente com o tempo, e a citação de Mestre Imamura dá indícios disso, a autoridade dos antepassados no legado para as gerações futuras é outro elemento necessário na análise dos mestres entrevistados sobre a consideração de uma arte marcial tradicional.

É na relação entre mestres e discípulos que se dá o lastro histórico ao tempo decorrido. Em outras palavras, o tempo é considerado na avaliação da tradição, uma vez que é o seu palco, mas são as relações de sucessão e de testemunho entre mestres e discípulos, os atores, que dão substância e vivacidade à tradição. A autoridade dos antepassados é evidenciada em uma fala da Professora Angela Soci: "é como se teu próprio espírito estivesse se comunicando com os espíritos dos ancestrais que desenvolveram essa tradição" (Professora Angela Soci. Entrevista em 11/12/2012).

Os discípulos, nessa relação com os mestres, "crescem em direção ao passado", de acordo com Arendt (2011), pois buscam a autoridade legitimadora de seus projetos na arte marcial no contato com mestres oriundos de genealogias que remetem às fundações dos sistemas. Mestre Thomaz é o único que faz justamente o caminho inverso: sua relação muito mais íntima com a genealogia, herdada por laços consanguíneos, dificultou o percurso de um caminho independente de seu mestre e pai, caminho este que foi construir na vertente esportiva do Kung Fu. Contra a colonização de sua identidade pela associação ao pai, Mestre Thomaz se tornou um dos mais reconhecidos mestres de Wushu Moderno, mas isso porque a genealogia já Ihe garantia a legitimidade enquanto mestre de Shaolin do Norte. Ademais, como nos revela Gadotti (1975), o mestre é o sujeito que trabalha para ser superado, que ensina o discípulo a agir por si mesmo sob um princípio de autoanulação. Em outras palavras, bons mestres fornecem um testemunho sem impedir que seus discípulos trilhem seu próprio caminho, mesmo que isso signifique ir ao encontro de outro mestre ou até mesmo de outra vertente da prática.

O imperativo do passado, que se faz presente pela autoridade daqueles que estavam próximos à fundação do estilo, sistema, família, ou escola de arte marcial, não deixa de repercutir mesmo quando envolvido e reinterpretado sob uma óptica esportiva. Aqueles mestres que estão mais próximos da gestão das instituições reguladoras do Kung Fu no Brasil são muitas vezes interpelados pela tentativa de filiação de práticas as quais eles não consideram tradicionais, 
pois não apresentam antiguidade lastreada pela genealogia. Mestre Thomaz os valoriza, pois "por trás desses estilos não tradicionais tem o tradicional na fortaleza dele"; eles não foram inventados sem um esforço de observação histórica e técnica atenta de seus criadores.

\begin{abstract}
A nossa federação, da filiação com direção, por exemplo, pra aceitar um estilo tem que ter um mapeamento na federação. A federação exige esse mapeamento pra que eles participem desse nosso regulamento. Então antes disso ele precisa saber da onde vem a árvore genealógica, como que é o histórico dele e os nomes dos Katis. Aí, eu acho que tem alguns estilos, cada estilo já tem esse... E os novos também têm, também têm. Então eu já tive, já tive esse preconceito, mas hoje eu... Olha, o valor que eu tenho por trás disso é tão forte que às vezes eu olho pro Kung Fu não tradicional, eu enxergo com bons olhos, se ele souber inventar alguma coisa, eu olho com bons olhos. Eu não tenho essa capacidade criativa pra inventar estilo, não tenho. (Mestre Thomaz Chan. Entrevista concedida ao autor em 29/11/2012).
\end{abstract}

Já Mestre Paulo diferencia, na Liga que preside, a filiação de um estilo do seu reconhecimento. A filiação não depende de análise da genealogia e de sua fundação ou da qualidade técnica de seu método, mas sim da documentação legal necessária para associar uma entidade à Liga. Já o reconhecimento implica estudo histórico do estilo, conferência da genealogia e da origem em alguma arte chinesa:

Porque muitos mestres hoje têm academia legalizada, direitinho, registrada, com CNPJ, com estatuto, tudo direitinho, mas o estilo que ele ensina foi realmente inventado. Mas o que importa é a documentação que o cara tem. [...] [Mas, para 0 reconhecimento] não basta isso, porque não tô filiando você, estamos fazendo um reconhecimento do seu estilo. Então é diferente. Agora se a gente tivesse fazendo o reconhecimento de estilo, aí sim, aí ia buscar a origem do seu estilo na China, quem foi o seu mestre, de onde veio, aquilo, aquilo outro (Mestre Paulo da Silva. Entrevista em 17/09/2013).

Se a relevância do tempo e da autoridade dos antepassados são pontos consensuais nas interpretações dos mestres, as divergências acontecem quando se evidenciam os modos como a importância da tradição é justificada. O passado e o testemunho dos antepassados são mobilizados de acordo com uma dinâmica que atinge o campo do Kung Fu de maneira decisiva. Trata-se da relação entre manutenção e transformação da tradição.

\title{
A tradição é tão atual quanto antigamente. Por que mudar?
}

A abordagem da tradição enquanto manutenção daquilo que, desde a fundação, opera de maneira a produzir sentidos àqueles que estão envolvidos na prática é recorrente no universo das artes marciais chinesas e está presente na fala de alguns dos mestres entrevistados. Recorrendo à Bourdieu (2004), essa é uma visão que propõe que a tradição é aquilo que o Kung Fu tem de permanente, de continuidade do passado. Em outras palavras, a tradição é reconhecida por ser o componente estrutural dessa prática corporal. Mudanças nessa estrutura são, portanto, observadas com ressalvas e é da responsabilidade dos líderes de cada sistema salvaguardá-la.

Mestre Francisco Nobre é exemplo de liderança preocupada com as questões de, por um lado, manutenção em relação ao passado e, por outro, do legado em relação às gerações futuras. A intenção de propagar por mais mil anos uma história de mil anos, tal como diz a sua mestra, se sustenta somente por essa concepção de tradição enquanto estrutura permanente 
do sistema. Tal estrutura deve ser mantida, pois alude a um fluxo ininterrupto desde a criação até a atualidade. Desse modo, dizer que uma arte tem mil anos é defender a sua linearidade e manutenção tal qual se imagina que tenha sido na fundação. Mestre Francisco torna isso explícito ao declarar o seu conceito sobre tradição:

Dentro da arte marcial, tradição, numa palavra, seria manter. Manter o quê? Manter o primeiro aspecto. Porque a gente sempre fala da tradição, um monte de coisa que é tradição, é tradicional, mas acaba fugindo. Então, a tradição dentro do Kung Fu é manter o primeiro princípio, manter a visão do fundador, manter a visão do mestre, manter... é tanta coisa que... mas acho que tradição é isso, é manter o antigo, manter 0 antigo presente pras próximas gerações. Eu acho que essa é a tradição. (Mestre Francisco Nobre. Entrevista em 11/07/2013).

No mesmo sentido, Mestre Paulo da Silva alude a uma origem milenar das artes marciais no sentido de discernir entre um Kung Fu tradicional, que "existe há mais de cinco mil anos" e um Wushu Moderno, relacionado às "formas desenvolvidas pelo governo chinês [...] pra entrar nas olimpíadas". Mestre Thomaz Chan dialoga com esses pensamentos ao falar sobre a importância da tradição:

[...] É onde tudo começou, onde veio a essência, onde é o primeiro caminho. 0 tradicional é muito forte, não dá pra fugir da tradição, ele é a base, a essência. Ele é onde a gente pode penetrar e ter muitas visões. E é só na tradição que a gente consegue ver, né? Embora o que eu te falei do moderno, ele ajuda bastante, ele tem o seu mérito, é uma outra configuração. Mas ele [o tradicional] é tudo, é história, é onde detalhe por detalhe tem sentido. (Mestre Thomaz Chan. Entrevista concedida ao autor em 29/11/2012).

A condição aparentemente contraditória em que se encontram as falas desses mestres - voltar-se para a manutenção da fundação em detrimento dos processos históricos que atingiram as práticas - alude ao caráter conservador das "tradições inventadas" pela nobreza britânica dos estudos de Hobsbawm (2006) e ao caráter rebelde (mas também conservador) dos "costumes" da classe trabalhadora inglesa analisados por Thompson (1998).

Se Hobsbawm (2006) afirma que a proliferação discursiva sobre as tradições ocorre em momentos históricos nos quais há um solapamento de antigas tradições, é possível analisar que o conservadorismo fundamentado e expresso na manutenção, na permanência e na continuidade do passado é uma manifestação de resistência diante das racionalizações impostas pelo modelo esportivo europeu, que traz a novidade da padronização, da espetacularização e da centralidade na competição. Não é coincidência que os mestres que adotam o discurso da manutenção são os que mais dialogam, ainda que de modos distintos entre si, com o universo esportivo: há um reconhecimento de que este é o modelo consagrado de difusão das práticas corporais na atualidade, mas que, ao mesmo tempo em que se aproxima dele, deve-se "manter" os pés fincados na autoridade da fundação das artes marciais chinesas.

O (des)encontro com as manifestações do esporte europeu, ocorrido há pouco mais de um século, foi o provável disparador dos discursos de afirmação da tradição que remetem as artes marciais chinesas ao seu caráter milenar e permanente. Foi em meio ao contexto de intenso conflito e disputa por identidades culturais que as artes marciais foram tensionadas ora enquanto práticas ligadas com o "atraso civilizatório" do império chinês, ora com o reforço da identidade nacional, tão necessária para o estabelecimento da república (MORRIS, 2004, FAIRBANK; GOLDMAN, 2008, BROWNELL, 2008). Se o Estado adotou o modelo esportivo 
para as artes marciais chinesas com o intuito de lidar com essa questão paradoxal, é possível conceber que os discursos sobre os mitos fundadores e sobre a tradição milenar do Kung Fu também foram reforçados, ao mesmo tempo como contraponto e como lastro para a sustentação da esportivização.

A posição discursiva de Professora Angela ao afirmar que não deveria existir arte marcial não tradicional é ilustrativa dessa discussão que envolve tradição e modernidade. Mencionando o Tai Chi Chuan moderno, o qual, em sua visão, se volta para questões superficiais das técnicas e seu objetivo esportivo, afirma que a tradição é o que informa sobre o princípio com o qual o ser humano deve se conectar.

Eu acho que não deveria existir a arte marcial não tradicional. Mas, o ser humano é assim, não tem jeito. Hoje você tem, por exemplo, aquilo que a gente chama de Tai Chi Chuan moderno, né? Mas o moderno tem que estar baseado em alguma tradição. Eles pegaram os conhecimentos dos mestres Yang, Chi Manching, desenvolveram coisas, mas eles querem desvincular a tradição transformando isso em apenas uma técnica corporal. Eu acredito assim, que quem mantém a tradição é o ser humano. Por mais jovem que você seja, se você tiver o seu espírito conectado com o principio, você vai buscar aquilo que é tradicional e acaba sendo inevitável esse caminho (Professora Angela Soci. Entrevista em 11/12/2012).

As narrativas que apontam a manutenção, preservação e continuidade da tradição no Kung Fu podem ser vistas, portanto, como uma tentativa de problematização e resistência conservadora em relação às empreitadas que visam à esportivização da arte marcial e que tendem a diminuir o papel dos componentes históricos e simbólicos dessas práticas em benefício dos seus elementos atléticos e estéticos. Nesse sentido, essas manifestações clamam para a necessidade do "enraizamento" das práticas corporais das artes marciais atuais em relação à sua história e narrativas mitológicas, pautada na autoridade dos antepassados (ARENDT, 2011) e na consagração do tempo vivido por eles. Retomando a sua narrativa, Mestre Francisco Nobre analisa qual deve ser a resposta das artes marciais chinesas frente ao quadro de transformações pelo qual o mundo passa e se utiliza do exemplo das práticas religiosas como modelo comparativo que deve ser expandido também para o Kung Fu:

\footnotetext{
Vou falar uma coisa: uma pessoa falou uma vez pra mim, assim, que o mundo tá sempre em evolução, tá sempre evoluindo, que tudo tá se modificando, que as técnicas estão mudando, né? E eu percebi uma coisa, que o nosso, o Garra de Águia, ele é tradicional, porque os mestres, o fundador, os outros mestres, os monges, eles vieram mantendo essa tradição, mantendo esse princípio dessa tradição no início, quando foi fundado, ele é tão atual, quanto foi antigamente, né? Então, pra que mudar? Não existe a necessidade de mudar, tem que manter da mesma forma como era, que continua, é como a religião, né? Se for ver, a religião tem... o Cristianismo tem dois mil anos e ela é tão atual quanto antes, né? (Mestre Francisco Nobre. Entrevista em 11/07/2013).
}

A despeito de considerar que mesmo as religiões também passam por processos de transformação que abalam suas estruturas, a comparação é relevante por evidenciar quais são as referências que informam sobre as narrativas da manutenção: o caráter milenar, a ligação direta com o mito fundador e a semelhança entre as práticas do passado e as do presente. Desse modo, ao mesmo tempo em que a manutenção da tradição é uma manifestação que expressa ressalva ao discurso esportivo europeu, ela confere pouca relevância às transformações que fazem parte da própria história das artes marciais chinesas, culminando com o que elas são atualmente. Fazendo referência novamente a Bourdieu (2004), a história estrutural somente 
pode ser compreendida ao se considerar as mudanças no campo esportivo, ou seja, há uma interdependência entre estrutura e transformação que afasta a necessidade de uma separação conceitual tão demarcada entre ambas.

\section{Sabe por que a cultura chinesa é milenar? Porque ela sempre muda.}

Se a história estrutural das denominações de Kung Fu somente é compreendida pela análise de suas transformações, como seria possível associar a tradição - tão atravessada por narrativas envolvendo manutenção, preservação e permanências - à transformação de maneira não contraditória? Essa questão, aparentemente insolúvel tendo em vista os posicionamentos apresentados até agora, não parece ser obstáculo para uma elaboração conceitual que encara a tradição enquanto processo vivo. Nesse sentido, ainda que venha a ressaltar aspectos da manutenção em um momento posterior, Professora Angela apresenta um conceito de tradição que considera a atuação dos processos históricos na constituição da prática:

Tradição é uma via de acesso ao que há de mais espiritual no ser humano. Eu tenho visto isto em várias tradições, não só no Tai Chi não, mas eu entendo a palavra tradicional como uma via de acesso àquilo que te faz realmente procurar ser um ser humano melhor. Uma harmonia, harmonia de comunicação. Quando a tradição não é perdida, ela é transformada. A tradição não é religião. Ela não é uma coisa cristalizada. Tradição, ela é tradição porque ela é viva e ela é transmitida de geração em geração (Professora Angela Soci. Entrevista em 11/12/2012).

Novamente há a referência à religião como quadro comparativo com a tradição nas artes marciais chinesas, porém, por se tratar de uma fala que alude à transformação, a alusão é utilizada para demarcar recusa ao modelo religioso. Dessa forma, as falas de Mestre Francisco e Professora Angela, ao remeterem às práticas religiosas, corroboram a análise de que há duas narrativas distintas de abordagem para a justificativa da importância da tradição no Kung Fu e que ora se aproximam da necessidade de preservação, ora se referem à perspectiva da reatualização e da transformação contextual da tradição.

Desse modo, não se trata de transposição da experiência - e, portanto, de simples continuidade -, mas de repensar a vivência dos antepassados em contextos históricos e semânticos distintos, algo que exige esforço interpretativo e analítico. Tal perspectiva mantém paralelo, pois, com a concepção de autoridade trazida por Arendt (2011) na qual o testemunho dos antepassados acrescenta à experiência presente, mas que, ao mesmo tempo, não deve ser transportado automaticamente como modelo das relações humanas na atualidade, sob o risco de revelar-se tirânico. Além disso, aproxima-se da compreensão de que o discípulo não pode ser cópia do mestre, nem expressar adoração servil por ele, sendo estes sinais de um entendimento equivocado da relação entre mestre e discípulo: conforme alerta Gadotti (1975), o trabalho do mestre é afirmar o discípulo em sua própria existência e este, por sua vez, não se pode deixar dominar pela experiência do mestre. Tradição trata-se da fidelidade à caminhada, não ao caminho.

A narrativa de Mestre Imamura aprofunda a aproximação com esses dois referenciais teóricos ao comentar sobre a origem da legitimidade de um patrimônio cultural e a sua relação com a transmissão do legado entre os sujeitos envolvidos baseada na autorização dos mais antigos e que não segue da mesma maneira, pois cada geração constrói seu próprio legado:

O que caracteriza o patrimônio cultural intangível, ou a legitimidade dele, não é a semelhança com o original, mas é uma legitimidade que vem do quê? Da aceitação do legado, da passagem do legado de uma geração a outra, uma 
passagem autorizada, uma passagem tradicional, uma passagem legitimada pela geração anterior, então eu falo: "você é o mais qualificado de Ving Tsun", mas você tem sua visão, e não necessariamente é igual a minha, isso não faz o seu Kung Fu ilegítimo, muito pelo contrário, mas você aceitou. Por que eu sei que você é o melhor? Porque você aceitou o meu legado e agora, você está fazendo o seu [...]. E por isso que as artes marciais, verdadeiramente tradicionais, elas são válidas até hoje: quando você vê algum movimento anacrônico, que não faz sentido, aquela coisa toda, você pode ver, é a cópia do igual, é a repetição do igual, e não a renovação do semelhante (Mestre Leo Imamura. Entrevista em 17/08/2012).

Chama a atenção o fato de Mestre Imamura também considerar a atualidade das artes marciais chinesas tradicionais, mas de um ponto de vista distinto de Mestre Francisco. Se este defende que a atualidade é motivada pela manutenção da tradição que permanece desde a fundação, Imamura considera que não é a repetição, mas sim a renovação do legado que garante a atualidade. A transformação da tradição é também reconhecida pelo Mestre Sérgio Queiroz quando complementa e problematiza a narrativa de Mestre Francisco, demonstrando que, mesmo entre mestres de uma mesma denominação do Kung Fu, no caso o Garra de Águia da Família Lau, há nuances em relação às concepções sobre a tradição.

É que, na realidade, não é que a tradição não precisa mudar, a arte é feita de aspectos evolutivos e a tradição traz uma memória do por que as coisas se realizavam daquela maneira, naquele tempo. Então, o que eu acho que é interessante na tradição, é do poder observar o que, ao longo do tempo, continua sendo constante, tu entendeu? E o que, ao longo do tempo, foi tendo expectativas de mudança (Mestre Sérgio Queiroz. Entrevista em 11/07/2013).

As narrativas da manutenção e preservação da tradição, ainda que sejam relevantes diante da colonização esportiva e da proliferação de ramificações que não possuem lastro histórico, são problematizadas por aquela que compreende a tradição como um processo em que cabem transformações baseadas na observação dos meandros da historiografia do Kung Fu e no caráter inacabado da obra de um mestre para com os discípulos. Se o título do tópico anterior questionava a necessidade de mudança, uma possível resposta a ele abrangeria o caráter interpretativo $e$ histórico da tradição que projeta a sua permanência na mobilidade e na transformação:

Eu vou citar uma situação que eu passei, quando estava em Nova York: o meu mestre, ele tinha um aluno que era um diretor de Hong Kong, diretor de cinema, uma pessoa muito culta, chamada Patrick, Patrick Kong. Em chinês, ele chamava Leung Kong e ele via a minha dedicação, porque eu tava lá estudando a tradição, aquela coisa toda, queria saber toda tradição e aí um dia ele chegou pra mim e falou assim: "Leo, você sabe por que a tradição chinesa tem mais de 4.000 anos?". Eu falei: "Não". "Porque ela está sempre mudando" (Mestre Leo Imamura. Entrevista em 17/08/2012).

Desse modo, se essas narrativas consideram a transformação da tradição, elas não 0 fazem com o intuito de rejeitá-la. Em certo ponto, também estão interessadas em sua permanência, mas constatam que isso não pode ser realizado sem um esforço para desvelar os elementos históricos que retiram a legitimidade da tradição. É nesse sentido que também rejeitam, talvez com ainda mais força, a esportivização da arte marcial. Assim, aludem ao fato de que as tradições - além do caráter intrínseco da relação entre mestres e discípulos - se relacionam intensamente com os processos históricos e políticos de uma sociedade. Em última análise, as narrativas que remetem às transformações da tradição apontam para a necessidade 
dos envolvidos com as artes marciais em apreciar, estudar e criticar os sentidos trazidos pela tradição, muitas vezes produzidos em e para contextos distintos.

\section{CONSIDERAÇÕES FINAIS}

Em todas as entrevistas, os mestres evocam dois fatores imprescindíveis na conceituação da tradição: o tempo e a genealogia. Em outras palavras, o que confere legitimidade às artes marciais chinesas tradicionais, de acordo com os mestres, é a confluência da sua antiguidade com o alicerce histórico do testemunho dos antepassados. Nesse sentido, não se questiona a importância da tradição para a autenticidade de uma arte marcial chinesa.

Contudo, as narrativas apontaram para duas narrativas distintas no que se refere 1) à tradição enquanto manutenção da experiência do passado (estrutura) e 2) à consideração das transformações sofridas pela tradição. A primeira visa à reprodução da experiência do passado no presente por meio da relação com a fundação, em uma linha direta de sucessão. Há uma preocupação com a história da arte marcial, mas uma análise propriamente historiográfica não é enfatizada, sendo que a narrativa mitológica e simbólica, principalmente relacionada ao mito fundador e à ancestralidade, é o seu cerne.

Já a segunda busca uma contextualização da tradição e intercede por uma análise mais cuidadosa em relação ao processo histórico de cada sistema de Kung Fu, objetivando compreender em que momentos a tradição foi atravessada e modificada em razão de acontecimentos histórico-políticos. Nesse sentido, gira em torno da crítica à reprodução da tradição e da necessidade de uma postura interpretativa do legado dos antepassados.

Chama a atenção o fato de que ambas são reticentes em relação ao modelo esportivo, mas sob perspectivas diferentes: se uma alude à carência de conteúdos simbólicos e filosóficos na ênfase dada ao tecnicismo, à competitividade e ao apelo estético das manifestações esportivas, a outra pontua as questões que permearam as artes marciais em relação à dominação política e cultural que sofreram em determinados momentos da história.

É nesse sentido que parece ser pertinente afirmar que o debate referente à tradição nas artes marciais chinesas configura um campo também de uma disputa em torno de sentidos e significados. Desse modo, a presente pesquisa evidenciou que essa circulação de narrativas dialógicas, ora consensuais, ora conflitantes, é substancial para a compreensão do campo esportivo do Kung Fu no Brasil. Além disso, as artes marciais chinesas demonstraram ser um campo privilegiado que permite aos envolvidos entrar em contato com questões sofisticadas a respeito das relações estreitas que a história, a política, a cultura e a sociedade podem estabelecer com as práticas corporais.

\section{REFERÊNCIAS}

APOLLONI, Rodrigo Wolff. Shaolin à brasileira: estudo sobre a presença e a transformação de elementos religiosos orientais no Kung Fu praticado no Brasil. 2004. 221 f. Dissertação (Mestrado) Pontifícia Universidade Católica de São Paulo, São Paulo, 2004.

ARENDT, Hannah. O que é autoridade? In: ARENDT, Hannah. Entre o passado e o futuro. São Paulo: Perspectiva, 2011. p. 127-187. 
BOSI, Ecléa. 0 tempo vivo da memória: ensaios de psicologia social. São Paulo: Ateliê, 2004.

BOURDIEU, Pierre. Programa para uma sociologia do esporte. In: BOURDIEU, Pierre. Coisas ditas. São Paulo: Brasiliense, 2004. pp. 207-220.

BROWNELL, Susan. Beijing's games: what the Olympics mean to China. Lanham: Rowman and Littlefield, 2008.

FAIRBANK, John King; GOLDMAN, Merle. China: uma nova história. Porto Alegre: L\&PM, 2008.

FERREIRA, Fernando Dandoro Castilho. A inserção do Kung Fu no Brasil na perspectiva dos mestres pioneiros. 2013. 181 f. Dissertação (Mestrado) - Curso de Educação Física, Universidade Federal do Paraná, Curitiba, 2013.

FERREIRA, Fernando Dandoro Castilho; MARCHI JÚNIOR, Wanderley; CAPRARO, André Mendes. O "Kung Fu" no Brasil na perspectiva dos mestres pioneiros: problemas e perspectivas no uso da história oral como instrumental de análise. Revista Brasileira de Educação Física e Esporte, São Paulo, v. 28, n. 1, p.65-75, jan./mar. 2014.

GADOTTI, Moacir. Comunicação docente: ensaio de caracterização da relação educadora. São Paulo: Loyola, 1975.

HALBWACHS, Maurice. A memória coletiva. São Paulo: Centauro, 2006.

HOBSBAWM, Eric. Introdução: a invenção das tradições. In: HOBSBAWM, Eric; RANGER, Terence. (Org.). A invenção das tradições. São Paulo: Paz e Terra, 2006. p. 9-23.

LIMA, David Alves de Souza. Técnico-mestre e atleta-herói: uma leitura simbólica dos mitos de Quíron e do herói entre técnicos de voleibol. 2012. 88 f. Dissertação (Mestrado) - Escola de Educação Física e Esporte, Universidade de São Paulo, São Paulo, 2012.

MARTA, Felipe Eduardo Ferreira. A memória das lutas ou o lugar do "DO": as artes marciais e a construção de um caminho oriental para a cultura corporal na cidade de São Paulo. 2009. 213 f. Tese (Doutorado) - Pontifícia Universidade Católica de São Paulo, São Paulo, 2009.

MEIHY, José Carlos Sebe Bom; HOLANDA, Fabíola. História oral: como fazer, como pensar. São Paulo: Contexto, 2007.

MORRIS, Andrew. The marrow of the nation: a history of sport and physical culture in Republican China. Los Angeles: University of California, 2004.

NASCIMENTO, Paulo Henrique. Mulheres no pódio: as histórias de vida das primeiras medalhistas olímpicas brasileiras. 2012. 86 f. Dissertação (Mestrado) - Escola de Educação Física e Esporte, Universidade de São Paulo, São Paulo, 2012.

NUNES, Alexandre Velly. A influência da imigração japonesa no desenvolvimento do judô brasileiro: uma genealogia dos atletas brasileiros medalhistas em jogos olímpicos e campeonatos mundiais. 2011. 197 f. Tese (Doutorado) - Escola de Educação Física e Esporte, Universidade de São Paulo, São Paulo, 2011.

RUBIO, Katia. Medalhistas olímpicos brasileiros: histórias, memórias e imaginário. São Paulo: Casa do Psicólogo, 2006.

THOMPSON, Edward Palmer. Costumes em Comum: estudos sobre a cultura popular tradicional. São Paulo: Companhia das Letras, 1998.

TRALCI FILHO, Marcio Antonio. Artes marciais chinesas: histórias de vida de mestres brasileiros e as tensões entre a tradição e o modelo esportivo. 2014. 241 f. Dissertação (Mestrado) - Curso de Educação Física, Universidade de São Paulo, São Paulo, 2014. 